\title{
New MR Imaging Assessment Tool to Define Brain Abnormalities in Very Preterm Infants at Term
}

\author{
H. Kidokoro, J.J. Neil, and T.E. Inder
}

\begin{abstract}
BACKGROUND AND PURPOSE: WM injury is the dominant form of injury in preterm infants. However, other cerebral structures, including the deep gray matter and the cerebellum, can also be affected by injury and/or impaired growth. Current MR imaging injury assessment scales are subjective and are challenging to apply. Thus, we developed a new assessment tool and applied it to MR imaging studies obtained from very preterm infants at term age.
\end{abstract}

MATERIALS AND METHODS: MR imaging scans from 97 very preterm infants ( $<30$ weeks' gestation) and 22 healthy term-born infants were evaluated retrospectively. The severity of brain injury (defined by signal abnormalities) and impaired brain growth (defined with biometrics) was scored in the WM, cortical gray matter, deep gray matter, and cerebellum. Perinatal variables for clinical risks were collected.

RESULTS: In very preterm infants, brain injury was observed in the WM $(n=23)$, deep GM $(n=5)$, and cerebellum ( $n=23)$. Combining measures of injury and impaired growth showed moderate to severe abnormalities most commonly in the WM ( $n=38)$ and cerebellum $(n=32)$ but still notable in the cortical gray matter $(n=16)$ and deep gray matter $(n=11)$. WM signal abnormalities were associated with a reduced deep gray matter area but not with cerebellar abnormality. Intraventricular and/or parenchymal hemorrhage was associated with cerebellar signal abnormality and volume reduction. Multiple clinical risk factors, including prolonged intubation, prolonged parenteral nutrition, postnatal corticosteroid use, and postnatal sepsis, were associated with increased global abnormality on MR imaging.

CONCLUSIONS: Very preterm infants demonstrate a high prevalence of injury and growth impairment in both the WM and gray matter. This MR imaging scoring system provides a more comprehensive and objective classification of the nature and extent of abnormalities than existing measures.

ABBREVIATIONS: $\mathrm{GM}=$ gray matter; VPT = very preterm

W ith advances in obstetric and neonatal care of the preterm infant, the incidence of cerebral palsy has been decreasing, ${ }^{1,2}$ yet preterm-born children remain at high risk for cognitive, behavioral, academic, and social challenges later in life. ${ }^{3,4}$ The neuropathologic conditions leading to adverse neurodevelopmental sequelae in later life in former preterm infants are areas of active research and clinical focus.

Received August 17, 2012; accepted after revision January 8, 2013.

From the Departments of Pediatrics (H.K., J.J.N., T.E.I.), Neurology (J.J.N., T.E.I.), and Radiology (J.J.N., T.E.I.); Washington University in St. Louis, St. Louis, Missouri.

Funding/Support: National Institute of Child Health and Development (R01HD057098; 1POHD062171) and the Doris Duke Charitable Foundation.

Contributions: H.K. wrote the first draft, and all authors reviewed the final version of the manuscript. T.I. and J.N. have been principal investigators in the grants that collected the data presented in this study.

Please address correspondence to Terrie E. Inder, MBChB, MD, Departments of Pediatrics, Neurology, and Radiology; Washington University in St. Louis, 660 South Euclid Ave, St. Louis, MO 63110; e-mail: inder_t@kids.wustl.edu

- Indicates open access to non-subscribers at www.ajnr.org

http://dx.doi.org/10.3174/ajnr.A3521
MR imaging plays a crucial role in the identification of structural brain abnormalities, and the cerebral WM is the most commonly identified site for brain injury in the preterm infant. ${ }^{5}$ However, recent studies have also highlighted the significant involvement of the cortical GM, deep GM, and cerebellum. ${ }^{6-8}$ In addition to brain injury identified by signal abnormalities on conventional (T1- and T2-weighted) MR imaging, 3D volumetric approaches with MR imaging have defined global and regional alterations in brain structure in former preterm children. ${ }^{9-11}$ Thus, to fully capture the effect of preterm birth on the immature brain, a systematic assessment of both brain injury and altered brain growth is required.

Several MR imaging evaluation scales have been developed to define the severity of brain abnormality at term-equivalent postmenstrual age and to predict neurodevelopmental outcome in preterm infants. ${ }^{12-14}$ However, these scoring systems often address only cerebral WM and cortical GM and may thereby underestimate the full extent of brain abnormalities. In addition, the 
scorings in this scale are somewhat subjective, with variable relationships to neurodevelopmental outcome.

The aim of our study was to develop a new scoring system for conventional MR imaging that more comprehensively and objectively defines both brain injury and impaired brain growth. This scoring system was applied to MR imaging studies obtained from VPT infants at term-equivalent postmenstrual age to characterize brain injury in this population. Perinatal risk factors for these abnormalities were also explored.

\section{MATERIALS AND METHODS \\ Participants}

VPT infants ( $<30$ weeks' gestation) were recruited between April 2007 and June 2010 at St. Louis Children's Hospital. Of 121 infants recruited, 97 survivors (80\%) fulfilled the criteria of having undergone MR imaging at $\geq 36$ to $\leq 42$ weeks' gestation. During the same study period, term-born control infants were also enrolled. They were required to have mothers $>18$ years old who received regular prenatal care without medications or drug/alcohol use. In addition, the control infants did not receive any resuscitative procedures or neonatal medical care after birth. All infants were enrolled in the study after their parents had signed informed consent. The study protocols were approved by the local human research and ethics bodies.

\section{MR Imaging Acquisition}

MR imaging was undertaken by using a 3T Tim Trio system (Siemens, Erlangen, Germany) without sedation and included anatomic images obtained with an axial magnetization-prepared rapid acquistion of gradient echo T1-weighted sequence (TR, $1500 \mathrm{~ms}$; TE, $3 \mathrm{~ms}$; voxel size, $1 \times 0.7 \times 1 \mathrm{~mm}^{3}$ ), and a turbo spin-echo T2-weighted sequence (TR, $8600 \mathrm{~ms}$; TE, $160 \mathrm{~ms}$; voxel size, $1 \times 1 \times 1 \mathrm{~mm}^{3}$; echo-train length, 17).

\section{MR Imaging Assessment}

A standardized scoring system was used to evaluate cerebral WM and cortical GM abnormalities in a similar fashion to our previous study, ${ }^{12}$ augmented with quantitative biometrics. In addition, scales for the deep GM and cerebellum were developed and were included. All of the qualitative and quantitative assessments of MR images were performed by a single neonatal neurologist (H.K.) with sufficient experience to assess clinical MR images. Interobserver reliabilities (intraclass correlation coefficients) from 20 scans scored by 2 observers (H.K., T.I.) and intraobserver reliabilities (H.K.) from 20 scans scored 1 month apart by a single observer were $>0.90$ in the qualitative assessment. No infant had changed category of scoring between raters.

\section{Cerebral WM Abnormality}

Cerebral WM abnormality was graded on a scale between zero and 4 for 6 variables: 1) cystic degeneration, 2) focal signal abnormalities, 3) delayed myelination, 4) thinning of the corpus callosum, 5) dilated lateral ventricles, and 6) reduction of WM volume (Fig 1 and Table 1). Thinning of the corpus callosum was assessed with measurements of callosal thickness at 3 positions (genu, midportion of the body, and splenium) on a midsagittal section. Lateral ventricular dilation was assessed by measurement of the lateral ventricular diameter on a coronal section at the level of the ventricular atrium. Reduction of WM volume was determined by measurement of biparietal width on a coronal section by use of a DICOM viewer (Onis 2.3; DigitalCore, Tokyo, Japan) according to the definition in a previous report (Fig 2). ${ }^{15}$ Because biparietal width increases with postmenstrual age on MR imaging, we corrected the measured value with linear regression analysis according to the following equation: corrected biparietal width $=$ measured biparietal width + the slope $\times(40-$ postmenstrual age on MR imaging).

\section{Cortical GM Abnormality}

Cortical GM abnormality was graded on a scale between zero and 4 for 3 variables: 1) signal abnormality; 2) delayed gyration; and 3) dilated extracerebral CSF space, as previously reported. ${ }^{12}$ In this study, the degree of extracerebral CSF space was determined with a measurement of interhemispheric distance between the crowns of the superior frontal gyri at the same section for measurement of biparietal width (Fig 2).

\section{Deep GM and Cerebellar Abnormality}

New criteria for deep GM and cerebellar abnormalities were defined. These scores are a composite of signal abnormality (Fig 1) and volume reduction (Fig 2). Deep GM volume was assessed with a measurement of deep GM area on a single axial section on which the caudate heads, lentiform nuclei, and thalami were maximally visible. Cerebellar volume was categorized with a measurement of transcerebellar diameter according to the definition in a previous report. ${ }^{15}$ Because the deep GM area and transcerebellar diameter correlate positively with postmenstrual age on MR imaging, they were corrected by use of equations analogous to that above.

The total cerebral WM score was categorized into 4 grades: no (total score, 0-2), mild (total score, 3-4), moderate (total score, 5-6), or severe (total score, $\geq 7$ ) WM abnormality. Total cortical GM, deep GM, or cerebellar scores were also categorized into 4 grades: no (total score, 0 ), mild (total score, 1), moderate (total score, 2 ), and severe (total score $\geq 3$ ). Finally, a global brain abnormality score was calculated as the sum of these regional total scores and was classified as normal (total score, $0-3$ ), mild (total score, 4-7), moderate (total score, $8-11$ ), and severe (total score $\geq 12$ ).

Besides the scoring items, we also noted the presence or absence of subependymal hemorrhage and intraventricular hemorrhage, grading them on the basis of the Papile classification (grade I-III). ${ }^{16}$ Cystic WM lesions were categorized as cystic periventricular leukomalacia, periventricular hemorrhagic infarction, or other conditions. ${ }^{17}$

\section{Clinical Data}

All clinical variables were collected from maternal and infant hospital records. Chorioamnionitis was identified by use of clinical criteria consisting of maternal fever and/or elevated inflammatory markers on laboratory testing. Confirmed postnatal sepsis was defined as culture-positive sepsis. Necrotizing enterocolitis was defined according to the Bell criteria. ${ }^{18}$ Treated patent ductus arteriosus included pharmacologic and/or surgical treatment. Inotropic agents were used according to clinical needs for maintenance of systemic blood pressure. Postnatal steroids include hydrocortisone and dexamethasone.

AJNR Am J Neuroradiol 34:2208-14 Nov 2013 www.ajnr.org 

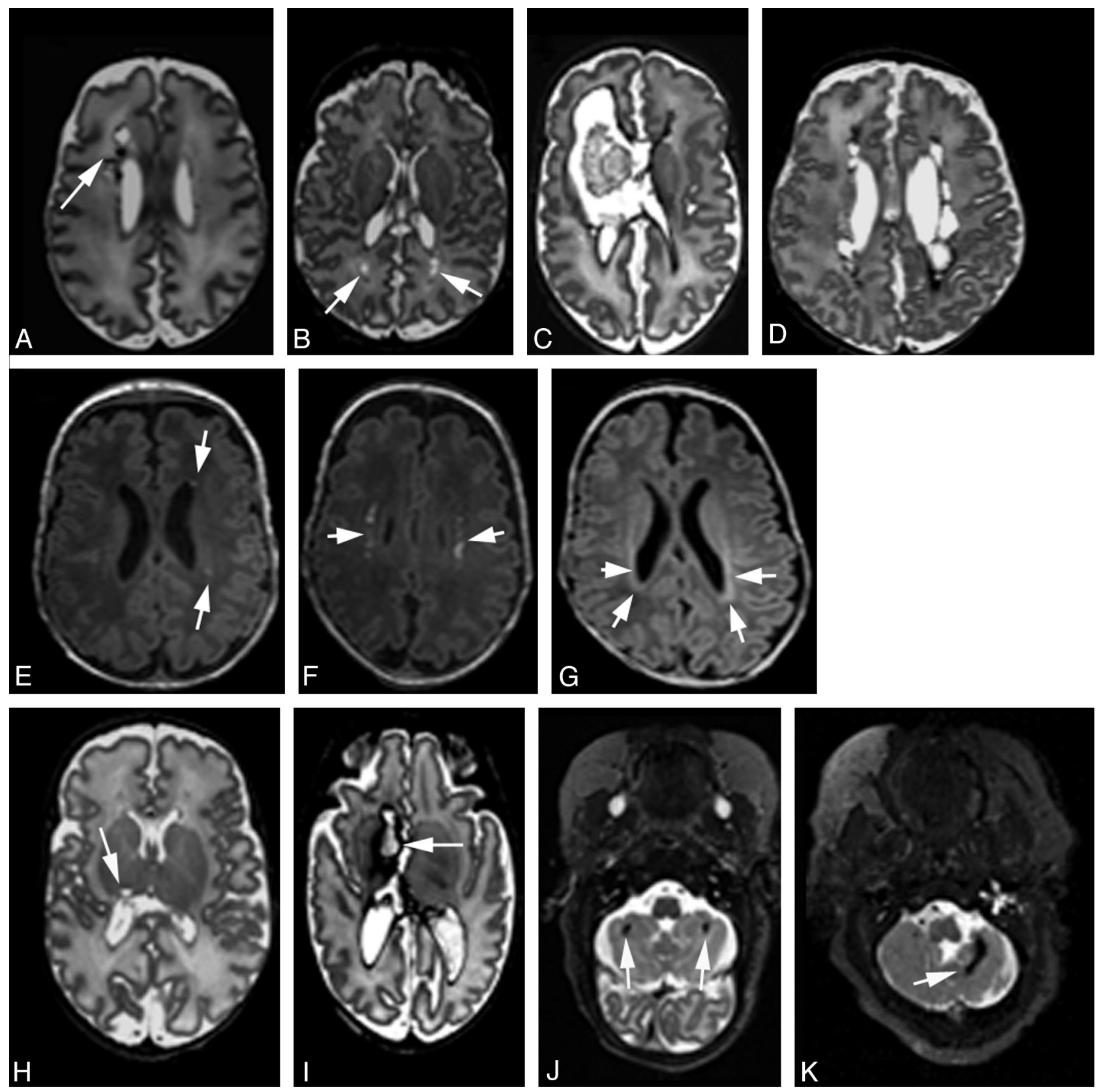

FIG 1. Representative MR images of regional injury. Axial T1- or T2-weighted MR images demonstrating classification of cystic WM lesions (A-D), focal WM signal abnormalities ( $E-G)$, deep $G M$ lesions ( $H$ and $I)$, and cerebellar lesions $($ and $K)$. Cystic WM lesions are defined by their extent: focal unilateral (arrow, A), focal bilateral (arrows, B), extensive unilateral (C), and extensive bilateral (D). Focal WM signal abnormalities are classified as focal punctate (arrows, E), extensive punctate (arrows, F), or linear lesions corresponding to gliosis (arrows, G). Deep GM and cerebellar injuries are classified into 4 grades by their extent. Representative images of focal unilateral (arrow, $H$ ) or extensive unilateral (arrow, I) deep GM lesions, and images of focal bilateral (arrows, J) or focal extensive (arrow, $K$ ) cerebellar lesions are shown.

\section{Statistical Analyses}

Data were analyzed with SPSS version 20.0 software (SPSS, Chicago, Illinois). Student $t$ test or analysis of variance was used when continuous parametric variables were compared between 2 or 3 groups. Mann-Whitney $U$ tests or Kruskal-Wallis tests were used to compare continuous nonparametric variables. $\chi^{2}$ tests were used with categoric variables. Simple linear regression analysis was used to obtain the slopes of the association between different measurements and postmenstrual age on MR imaging. Two-sided $P$ values $<.05$ were used to indicate statistical significance.

\section{RESULTS}

\section{Participants}

For the 97 VPT infants, the mean (SD) gestational age at birth was 26.7 (1.8) weeks, and mean birth weight was 949 (250) g. The VPT group included 6 small-for-gestational-age infants (birth weight of $<$ -2 SD for gestational age), 43 male infants (44\%), and 64 singletons (66\%). In the 22 term-born infants, mean gestational age at birth was 39.1 (1.0) weeks, and mean birth weight was 3285 (508) g. The term group included 9 male infants (41\%), and all of the infants were singleton with age-appropriate birth weight. The mean postmen- 
Table 1: Prevalence of infants with each item in cerebral WM score (VPT infants/term infants)

\begin{tabular}{|c|c|c|c|c|c|}
\hline \multirow[b]{2}{*}{ Variables } & \multicolumn{5}{|c|}{ WM Score } \\
\hline & Score 0 & Score 1 & Score 2 & Score 3 & Score 4 \\
\hline \multicolumn{6}{|l|}{ Cerebral WM } \\
\hline Cystic lesions & None $(90 / 22)$ & Focal unilateral (3/0) & Focal bilateral (1/0) & $\begin{array}{l}\text { Extensive unilateral } \\
(2 / 0)\end{array}$ & $\begin{array}{l}\text { Extensive bilateral } \\
(1 / 0)\end{array}$ \\
\hline Focal signal abnormality & None $(77 / 20)$ & Focal punctate $(13 / 2)$ & $\begin{array}{l}\text { Extensive punctate } \\
\qquad(5 / 0)\end{array}$ & Linear $(2 / 0)$ & \\
\hline Myelination delay & $\begin{array}{l}\text { PLIC \& corona } \\
\text { radiata }(65 / 22)\end{array}$ & Only PLIC (26/0) & $\begin{array}{l}\text { Minimal—no PLIC } \\
(6 / 0)\end{array}$ & & \\
\hline $\begin{array}{l}\text { Thinning of the corpus } \\
\text { callosum }\end{array}$ & None $(40 / 18)$ & $\begin{array}{l}\text { Partial (genu/body } \\
\quad<1.3 \mathrm{~mm} \text { or splenium } \\
\quad<2.0 \mathrm{~mm} \text { ) }(53 / 4)\end{array}$ & $\begin{array}{l}\text { Global (genu/body } \\
<1.3 \mathrm{~mm} \text { and } \\
\text { splenium }<2.0 \mathrm{~mm} \text { ) } \\
(4 / 0)\end{array}$ & & \\
\hline Dilated lateral ventricles & $\begin{array}{l}\text { Both sides VD } \\
\quad<7.5 \mathrm{~mm}(26 / 17)\end{array}$ & $\begin{array}{l}\text { One side } 7.5 \mathrm{~mm} \\
\leq \mathrm{VD}<10 \mathrm{~mm} \\
(19 / 4)\end{array}$ & $\begin{array}{l}\text { Both sides } 7.5 \mathrm{~mm} \\
\leq \mathrm{VD}<10 \mathrm{~mm} \text { or } \\
\text { one side } \mathrm{VD} \geq 10 \mathrm{~mm} \\
(42 / 1)\end{array}$ & $\begin{array}{l}\text { Both sides VD } \\
\qquad 10 \mathrm{~mm}(10 / 0)\end{array}$ & \\
\hline Volume reduction & $\begin{array}{l}\text { CBPW } \geq 77 \mathrm{~mm} \\
(21 / 19)\end{array}$ & $\begin{aligned} 77 \mathrm{~mm} & >\text { cBPW } \\
& \geq 72 \mathrm{~mm}(30 / 2)\end{aligned}$ & $\begin{array}{l}72 \mathrm{~mm}>c \text { cBPW } \\
\geq 67 \mathrm{~mm}(40 / 1)\end{array}$ & $\begin{array}{c}67 \mathrm{~mm}>\mathrm{CBPW} \\
(6 / 0)\end{array}$ & \\
\hline
\end{tabular}

Note:-CBPW indicates corrected biparietal width; PLIC, posterior limb of internal capsule; VD, ventricular diameter.
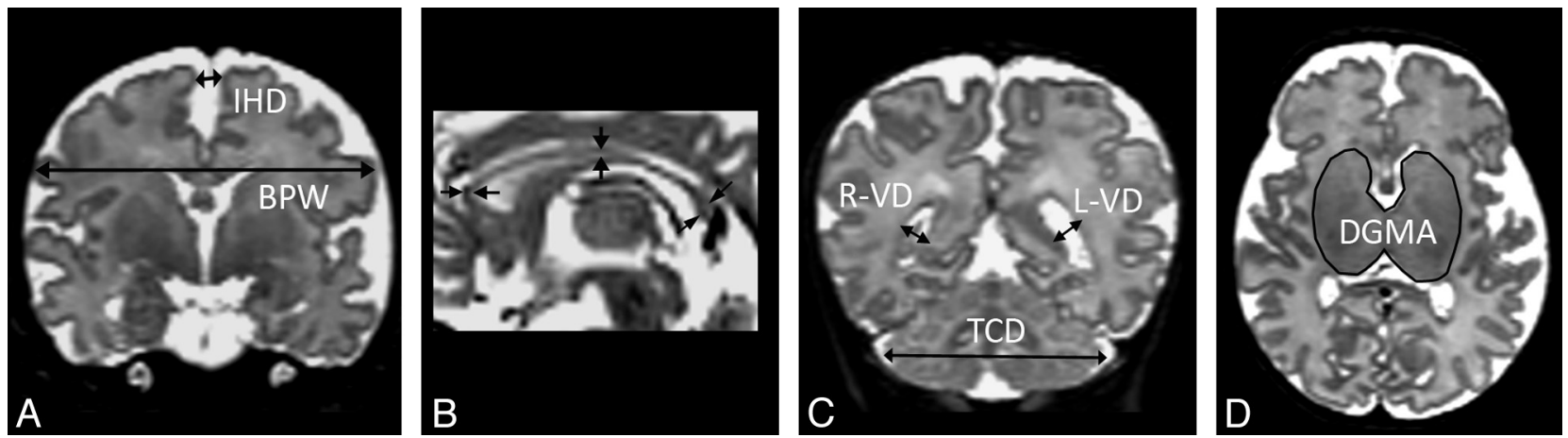

FIG 2. Regional measurements. A, Biparietal width (BPW) and interhemispheric distance (IHD) are measured on a single coronal section by use of the cochlea and basilar truncus as landmarks. B. Callosal thickness is measured on a midsagittal view at 3 different regions: the genu, the midportion, and the splenium. $C$, Ventricular diameters (VDs) and transcerebellar diameter (TCD) are measured on a coronal view at the level of the ventricular atrium. $D$, The deep GM area (DGMA) is measured on a single axial section at the level at which the caudate heads, the lentiform nuclei, and the thalami are maximally visible.

strual age on MR imaging in VPT infants was younger than that in term-born infants (38.0 [1.5] weeks vs 39.4 [1.1] weeks; $P=.001)$.

\section{Brain Measurements in VPT and Term Infants}

In the VPT group, a linear association was found between postmenstrual age at scan and biparietal width $(R=0.41 ; P<.001$; slope, $1.4 \mathrm{~mm} /$ week $)$, deep GM area $(R=0.36$; $P<.001$; slope, $0.26 \mathrm{~cm}^{2} /$ week $)$, and transcerebellar diameter $(R=0.35 ; P<.001$; slope, $0.83 \mathrm{~mm} /$ week), whereas no significant association was identified with interhemispheric distance, ventricular diameter, or callosal thickness. In contrast to the VPT group, no significant associations between postmenstrual age at scan and any brain measurements were observed in the term group.

Mean corrected biparietal width and corrected transcerebellar diameter were $72.4(4.5) \mathrm{mm}$ and 49.2 (3.3) $\mathrm{mm}$ in the VPT group, whereas biparietal width and transcerebellar diameter in the term group were 81.7 (4.7) $\mathrm{mm}$ and $52.6(2.2) \mathrm{mm}$, respectively (both $P<.001$ ). Mean corrected deep GM area was 9.7 (1.0) $\mathrm{cm}^{2}$ in the VPT group, whereas deep GM area was $10.5(0.8) \mathrm{cm}^{2}$ in the term group $(P<.001)$. Interhemispheric distance, ventricular diameters, and callosal thickness were also different between the VPT group and the term group $(3.6$ [1.7] $\mathrm{mm}$ vs 2.6 [1.1] $\mathrm{mm}$ in interhemispheric distance, $P=.001 ; 7.6[1.8] \mathrm{mm}$ vs 6.2 [1.4] $\mathrm{mm}$ in right ventricular diameter, $P=.001 ; 7.9[2.2] \mathrm{mm}$ vs 6.3 $[0.8] \mathrm{mm}$ in left ventricular diameter, $P<.001 ; 1.8[0.4] \mathrm{mm}$ vs $2.3[0.6] \mathrm{mm}$ in the genu, $P=.002 ; 1.4[0.3] \mathrm{mm}$ vs $1.6[0.2] \mathrm{mm}$ in the body, $P=.004$; and $2.3[0.6] \mathrm{mm}$ vs $2.7[0.5] \mathrm{mm}$ in the splenium of the corpus callosum, $P=.011$ ).

\section{Prevalence of Each Finding in the Cerebral WM in VPT and Term Infants}

Table 1 shows the prevalence of abnormalities in the cerebral WM. For VPT infants, 7 infants (7\%) had cystic lesions, whereas 20 infants (21\%) had noncystic signal abnormalities in the WM. Myelination delay, thinning of the corpus callosum, dilated lateral ventricles, and volume reduction were also common in the VPT group. For the total WM score, 38 infants (39\%) were categorized as having moderate to severe abnormalities.

Table 2 shows the prevalence of each MR imaging finding in the cortical GM, deep GM, and cerebellum. Signal abnormality was rare in the cortical GM $(n=0)$ and deep GM $(n=5[5 \%])$, but it was common in the cerebellum $(n=23[24 \%])$ in VPT infants. Except for 1 cystic lesion in the pulvinar of the right thal- 
Table 2: Prevalence of infants with each item in GM or cerebellum score (VPT infants/term infants)

\begin{tabular}{|c|c|c|c|c|c|}
\hline \multirow[b]{2}{*}{ Variables } & \multicolumn{5}{|c|}{ GM or Cerebellum Score } \\
\hline & Score 0 & Score 1 & Score 2 & Score 3 & Score 4 \\
\hline \multicolumn{6}{|l|}{ Cortical GM } \\
\hline Signal abnormality & None $(97 / 22)$ & Focal unilateral $(0 / 0)$ & $\begin{array}{l}\text { Focal bilateral } \\
\qquad(0 / 0)\end{array}$ & $\begin{array}{l}\text { Extensive unilateral } \\
(0 / 0)\end{array}$ & $\begin{array}{l}\text { Extensive bilateral } \\
(0 / 0)\end{array}$ \\
\hline Gyral maturation & $\begin{array}{l}\text { Delay }<2 \text { weeks } \\
\quad(96 / 22)\end{array}$ & $\begin{array}{l}2 \leq \text { delay }<4 \text { weeks } \\
(1 / 0)\end{array}$ & $\begin{array}{l}\text { Delay } \geq 4 \text { weeks } \\
\quad(0 / 0)\end{array}$ & & \\
\hline $\begin{array}{l}\text { Increased extracerebral } \\
\text { space }\end{array}$ & $\begin{array}{l}\mathrm{IHD}<4 \mathrm{~mm} \\
\quad(61 / 20)\end{array}$ & $\begin{array}{l}4 \mathrm{~mm} \leq \mathrm{IHD}<5 \mathrm{~mm} \\
(20 / 2)\end{array}$ & $\begin{array}{c}5 \mathrm{~mm} \leq \mathrm{IHD} \\
<6 \mathrm{~mm} \\
(8 / 0)\end{array}$ & $\mathrm{IHD} \geq 6 \mathrm{~mm}(8 / 0)$ & \\
\hline \multicolumn{6}{|l|}{ Deep GM } \\
\hline Signal abnormality & None $(92 / 22)$ & Focal unilateral $(2 / 0)$ & $\begin{array}{l}\text { Focal bilateral } \\
\qquad(2 / 0)\end{array}$ & $\begin{array}{l}\text { Extensive unilateral } \\
(0 / 0)\end{array}$ & $\begin{array}{l}\text { Extensive bilateral } \\
(1 / 0)\end{array}$ \\
\hline Volume reduction & $\begin{array}{l}\text { CDGMA } \geq 9.5 \\
(53 / 20)\end{array}$ & $\begin{array}{l}9.5>c D G M A \geq 8.5 \\
\quad(35 / 2)\end{array}$ & $\begin{array}{c}8.5>\text { CDGMA } \\
\geq 7.5(8 / 0)\end{array}$ & $7.5>\mathrm{cDGMA}(1 / 0)$ & \\
\hline \multicolumn{6}{|l|}{ Cerebellum } \\
\hline Signal abnormality & None $(74 / 22)$ & $\begin{array}{l}\text { Punctate unilateral } \\
(10 / 0)\end{array}$ & $\begin{array}{l}\text { Punctate bilateral } \\
(5 / 0)\end{array}$ & $\begin{array}{l}\text { Extensive unilateral } \\
\qquad(4 / 0)\end{array}$ & $\begin{array}{l}\text { Extensive bilateral } \\
(4 / 0)\end{array}$ \\
\hline Volume reduction & $\begin{array}{l}\text { CTCD } \geq 50 \mathrm{~mm} \\
(43 / 20)\end{array}$ & $\begin{array}{l}50 \mathrm{~mm}>c T C D \\
(31 / 2)\end{array}$ & $\begin{array}{l}47 \mathrm{~mm}>\mathrm{cTCD} \\
\geq 44 \mathrm{~mm}(18 / 0)\end{array}$ & $\begin{array}{l}\text { CTCD }<44 \mathrm{~mm} \\
(5 / 0)\end{array}$ & \\
\hline
\end{tabular}

Note:-cDGMA indicates corrected deep GM area $\left(\mathrm{cm}^{2}\right)$; cTCD, corrected transcerebellar diameter; IHD, interhemispheric distance.

Table 3: Effect of WM injury or intraventricular hemorrhage on deep GM or cerebellum in VPT infants

\begin{tabular}{|c|c|c|c|c|c|}
\hline & & \multicolumn{2}{|c|}{ Deep GM } & \multicolumn{2}{|c|}{ Cerebellum } \\
\hline & & $\begin{array}{c}\text { Signal } \\
\text { Abnormality } n(\%)\end{array}$ & $\begin{array}{c}\text { Corrected Deep } \\
\text { GM Area Mean (SD) }\end{array}$ & $\begin{array}{c}\text { Signal } \\
\text { Abnormality } n(\%)\end{array}$ & $\begin{array}{c}\text { Corrected } \\
\text { Transcerebellar } \\
\text { Diameter Mean (SD) }\end{array}$ \\
\hline \multirow[t]{2}{*}{ WM injury ${ }^{c}$} & Yes $(n=23)$ & $4(17)^{\mathrm{a}}$ & $9.4(1.2)^{\mathrm{b}}$ & $7(30)$ & $49.0(2.8)$ \\
\hline & No $(n=74)$ & $1(1.4)$ & $9.9(0.9)$ & $16(22)$ & $49.3(3.4)$ \\
\hline \multirow[t]{2}{*}{ Intraventricular hemorrhage } & Yes $(n=31)$ & $3(9.7)$ & $9.4(0.9)^{\mathrm{b}}$ & $12(39)^{b}$ & $48.2(3.5)^{b}$ \\
\hline & No $(n=66)$ & $2(3)$ & $9.9(1.0)$ & $11(17)$ & $49.7(3.0)$ \\
\hline
\end{tabular}

$a<.01$ vs without WM injury or intraventricular hemorrhage.

${ }^{b}<.05$.

'WM injury defined by the presence of cystic or focal signal abnormality.

Table 4: Perinatal variables and grade of global brain abnormality in VPT infants

\begin{tabular}{|c|c|c|c|c|c|}
\hline \multirow[b]{2}{*}{ Variables } & \multicolumn{4}{|c|}{ Global Brain Abnormality } & \multirow[b]{2}{*}{$P$ Value } \\
\hline & $\begin{array}{c}\text { Normal } \\
\text { (Score 0-3) } \\
n=18\end{array}$ & $\begin{array}{c}\text { Mild } \\
\text { (Score 4-7) } \\
n=45\end{array}$ & $\begin{array}{c}\text { Moderate } \\
\text { (Score 8-11) } \\
n=21\end{array}$ & $\begin{array}{c}\text { Severe } \\
\text { (Score } \geq 12 \text { ) } \\
n=13\end{array}$ & \\
\hline Gestation at birth (weeks) & $27.4(1.5)$ & $26.9(1.6)$ & $25.9(1.7)$ & $26.2(2.5)$ & .03 \\
\hline Birth weight $(g)$ & $1067(222)$ & $992(235)$ & 789 (185) & $897(305)$ & .002 \\
\hline Birth weight $<-2$ SD & $1(6 \%)$ & $3(7 \%)$ & $1(5 \%)$ & $1(8 \%)$ & .99 \\
\hline Male sex & $9(50 \%)$ & $22(49 \%)$ & $6(29 \%)$ & $6(46 \%)$ & .43 \\
\hline Singleton & $9(50 \%)$ & $13(29 \%)$ & $6(29 \%)$ & $5(39 \%)$ & .40 \\
\hline Critical Risk Index for Babies score & $1[1-4]$ & $2[1-5.5]$ & $4[1.5-7.5]$ & $4[1-9]$ & .06 \\
\hline Days of intubation & $1[0.75-2.25]$ & $2[1-8.5]$ & $4[1-28]$ & $21[3.5-52.5]$ & .004 \\
\hline Oxygen at 36 weeks & $5(28 \%)$ & $23(51 \%)$ & $12(57 \%)$ & $9(69 \%)$ & .12 \\
\hline Postnatal steroid use & 0 & $9(20 \%)$ & $10(48 \%)$ & $7(54 \%)$ & .001 \\
\hline Inotrope use & $1(6 \%)$ & $12(27 \%)$ & $11(52 \%)$ & $9(69 \%)$ & $<.001$ \\
\hline Patent ductus arteriosus & $5(28 \%)$ & $14(31 \%)$ & $11(52 \%)$ & $9(69 \%)$ & .04 \\
\hline Total parenteral nutrition & $10.5[9-16.5]$ & $16[12.5-26.5]$ & $29[14.5-47]$ & $25[10-36]$ & .004 \\
\hline Chorioamnionitis & $5(28 \%)$ & $19(42 \%)$ & $9(45 \%)$ & $4(31 \%)$ & .61 \\
\hline Confirmed sepsis & $2(11 \%)$ & $10(22 \%)$ & $9(43 \%)$ & $8(62 \%)$ & .007 \\
\hline Necrotizing enterocolitis & 0 & $2(4 \%)$ & $3(14 \%)$ & $2(15 \%)$ & .19 \\
\hline
\end{tabular}

Note:-Data are mean (SD), number (\%), or median [lower-upper quartile].

amus (Fig $1 H$ ), all of the other findings with signal abnormalities in the deep GM and the cerebellum corresponded to hemorrhagic lesions (ie, associated with shortened $\mathrm{T} 1$ and $\mathrm{T} 2$ relaxation time constants). Moderate to severe abnormalities in the cortical GM, deep GM, or cerebellum were observed in 16 infants (16\%), 11 infants (12\%), or 32 infants (33\%), respectively.

In contrast, none of the 22 term-born infants were classified as being in the moderate-to-severe category in any brain region. One term infant was classified as being in the mild category in the total WM score; 2 each were categorized as being in the mild category in the cortical GM score, deep GM score, and cerebellar score.

\section{Structural Correlation between WM Injury and Deep GM or Cerebellar Abnormality}

Of the 7 infants with cystic WM lesions, 3 were diagnosed with cystic periventricular leukomalacia and 4 with periventricular 
hemorrhagic infarction. All 7 infants were categorized as having moderate or severe WM abnormalities, whereas 20 infants with noncystic focal WM signal abnormalities varied in the total WM score according to differences in items related to volume. These cystic or focal WM signal abnormalities were associated with a reduced deep GM area but not with cerebellar abnormalities. On the other hand, intraventricular hemorrhage and/or periventricular hemorrhagic infarction were observed in 31 VPT infants (grade I $[n=8]$, grade II [ $n=18]$, grade III $[n=1]$, periventricular hemorrhagic infarction $[n=4])$ and were associated with cerebellar signal abnormalities and volume reduction (Table 3 ).

\section{Risk Factors for Grades of Global Brain Abnormality Score}

For the global brain score in VPT infants, 18 infants (19\%) were categorized as normal, $45(46 \%)$ as mild, 21 (22\%) as moderate, and $13(13 \%)$ as severe. All term-born infants were categorized as normal. Gestational age at birth and birth weight correlated with the grade of global brain abnormality, but postmenstrual age at scan did not $(P=.99)$. Multiple clinical risk factors were associated with worsening severity of global brain abnormalities, including days of intubation, postnatal corticosteroid use, demand for inotrope, treated patent ductus arteriosus, days of parenteral nutrition, and confirmed sepsis (Table 4).

\section{DISCUSSION}

Our study applies a new scoring system for conventional (T1- and T2-weighted) MR imaging to define the nature and extent of regional and global brain abnormalities in the VPT infant at termequivalent postmenstrual age. It extends the analysis of cerebral structures and incorporates objective measures of brain growth. Although primary injury, best defined by signal abnormalities on MR imaging, is important, impaired brain growth at term-equivalent postmenstrual age is also an important sequela of preterm birth. Impaired brain growth can result from secondary degeneration after injury and/or impairments in typical development that may result from poor nutrition ${ }^{19}$ or other adverse exposures, including postnatal corticosteroids ${ }^{20}$ and stress. ${ }^{21,22}$

Although the cerebral WM is a commonly injured area in the preterm infant because of its maturation-specific vulnerability, there is increasing recognition of brain injury beyond the cerebral WM. Recent investigations suggest that the deep GM and the cerebellum are also vulnerable to stresses encountered during the second to third trimesters. Histopathologic studies reveal that neuronal loss and gliosis occur within the thalamus of $40 \%-60 \%$ of VPT infants and in the cerebellum of $30 \% .{ }^{6}$ Our present study confirms that VPT infants have a high prevalence of primary brain injury in multiple regions including, but not limited to, the WM (24\%). A similar prevalence of injury was found in the cerebellum (24\%). Of note, no correlation was observed between the occurrence of WM and cerebellar injuries, indicating potentially independent pathologic pathways. Although the pathologic mechanism(s) of cerebellar hemorrhage remain uncertain, germinal matrix bleeding within the subpial external granular cell layer has been considered. ${ }^{23}$ Indeed, the etiologic factors reported for cerebellar hemorrhage are similar to those in intraventricular hemorrhage, including extreme prematurity, fetal distress, increased venous pressure, and impaired autoregulation of cerebral flow. ${ }^{24}$ In contrast, the pathogenesis for WM injury includes arterial hypoperfusion, systemic infection/inflammation, and the intrinsic vulnerability of preoligodendrocytes. ${ }^{5}$ Thus, considering its relatively high prevalence and likely etiologic differences from WM injury, a systematic assessment of cerebellar injury should be included in evaluations of the effect of preterm birth.

Using objective measurements, our study further demonstrates that each brain structure is reduced in size in the VPT infant assessed at term-equivalent postmenstrual age. Studies with $3 \mathrm{D}$ volumetric MR imaging methods demonstrate that preterm children have reduced volume in the cerebral WM, ${ }^{25,26}$ cortical GM, ${ }^{26,27}$ deep GM, ${ }^{28}$ and cerebellum, ${ }^{29,30}$ and such volume reductions correlate with neurodevelopmental disabilities. ${ }^{26,27,30}$ During the second to third trimesters, all brain structures are rapidly expanding. Such volume expansion is driven by the maturational processes of axon extension, dendrite elaboration, synaptogenesis, glial proliferation, and glial maturation. Widespread injury may have a particular effect on the thalamus. Thalamocortical neurons project to all parts of the cortical GM, and in turn, corticothalamic axons reach targeted thalamic neurons by term-equivalent postmenstrual age. Appropriate growth of the thalamus could be impaired by a primary insult, such as ischemia or hemorrhage, or by the secondary effects of degeneration or deafferentation caused by WM and/or cortical GM injury. ${ }^{31}$ Thus, deep GM volume may, in effect, integrate the consequences of injury to the WM and cortical GM, thereby more fully defining the effect of overall abnormalities $^{32,33}$ and reflecting the global nature of disturbances in brain development.

The scoring system that we have developed in our study helps to comprehensively define the complicated nature of brain abnormalities and to stratify the severity of brain abnormalities in the VPT infant. The grade of global brain abnormality defined with this scoring system was associated with clinical risk factors, including low systemic blood pressure, prolonged hypoxia, infection/inflammation, nutritional challenges, and drug therapies. Each of these causal factors is known to have a tight relationship to injury and/or disturbances of brain growth. ${ }^{34-36}$ This cohort of VPT infants has not yet completed neurodevelopmental assessment at age 2 years, but an evaluation of the relationship between these scores and short-term outcomes would provide further validation.

Qualitative assessment of brain volumes is challenging, and the reference standard for quantitative measurement of volumes is $3 \mathrm{D}$ volumetry. Although the MR imaging data used for our study are of sufficiently high spatial resolution $\left(1 \times 1 \times 1 \mathrm{~mm}^{3}\right)$ to use a volumetric approach, we chose instead to use simple $1 \mathrm{D}$ or $2 \mathrm{D}$ brain metrics to indicate volumes. This was because $3 \mathrm{D}$ volumetric data are not readily available in clinical practice because of computational requirements and the relatively lower spatial resolution of typical clinical images. The use of simpler brain metrics will make this scoring system more widely available. Furthermore, the brain metrics that we used show reasonable correlations with $3 \mathrm{D}$ volumetric measurements, ${ }^{15}$ and several of the regional metrics used in our study have been shown to predict subsequent motor or cognitive outcomes in the preterm population. ${ }^{37,38}$

\section{CONCLUSIONS}

We have developed a scoring system for conventional MR images that provides a comprehensive and objective characterization of 
regional and global brain injury and brain growth. This system may assist in clarifying the effect of preterm birth and the relationship between MR imaging-defined structural alterations of the brain at term-equivalent postmenstrual age and subsequent neurodevelopmental outcome in VPT survivors.

\section{ACKNOWLEDGMENTS}

We thank Drs. C. Vavasseur and T. Tjoeng; research staff K. Lukas, A. Barton, D. Alexopoulos, and J. Ackerman; and the families for their participation in this study.

Disclosures: The authors declare no conflicts of interest. We have not been paid to write this manuscript by pharmaceutical companies, medical equipment manufacturers, biomedical device manufacturers, or any companies with significant involvement in health care. Jeffrey Neil—RELATED: Grant: NIH.* Terrie Inder—RELATED: Grant: National Institutes of Health (NICHD RO1HD057098); UNRELATED: Expert Testimony: Occasional medical expert opinion in term infant brain injury cases. *Money paid to institution.

\section{REFERENCES}

1. Platt MJ, Cans C, Johnson A, et al. Trends in cerebral palsy among infants of very low birthweight $(<1500 \mathrm{~g})$ or born prematurely (<32 weeks) in 16 European centres: a database study. Lancet 2007;369:43-50

2. Robertson CM, Watt MJ, Yasui Y. Changes in the prevalence of cerebral palsy for children born very prematurely within a population-based program over 30 years. JAMA 2007;297:2733-40

3. Anderson P, Doyle LW. Neurobehavioral outcomes of school-age children born extremely low birth weight or very preterm in the 1990s. JAMA 2003;289:3264-72

4. Hack M, Flannery DJ, Schluchter M, et al. Outcomes in young adulthood for very-low-birth-weight infants. NEngl J Med 2002;346:149-57

5. Volpe JJ, Kinney HC, Jensen FE, et al. Reprint of "The developing oligodendrocyte: key cellular target in brain injury in the premature infant". Int J Dev Neurosci 2011;29:565-82

6. Pierson CR, Folkerth RD, Billiards SS, et al. Gray matter injury associated with periventricular leukomalacia in the premature infant. Acta Neuropathol 2007;114:619-31

7. Merrill JD, Piecuch RE, Fell SC, et al. A new pattern of cerebellar hemorrhages in preterm infants. Pediatrics 1998;102:E62

8. Messerschmidt A, Brugger PC, Boltshauser E, et al. Disruption of cerebellar development: potential complication of extreme prematurity. AJNR Am J Neuroradiol 2005;26:1659-67

9. Peterson BS, Vohr B, Staib LH, et al. Regional brain volume abnormalities and long-term cognitive outcome in preterm infants. JAMA 2000;284:1939-47

10. Nosarti C, Al-Asady MHS, Frangou S, et al. Adolescents who were born very preterm have decreased brain volumes. Brain 2002;125:1616-23

11. Peterson BS, Anderson AW, Ehrenkranz R, et al. Regional brain volumes and their later neurodevelopmental correlates in term and preterm infants. Pediatrics 2003;111:939-48

12. Inder TE, Wells SJ, Mogridge NB, et al. Defining the nature of the cerebral abnormalities in the premature infant: a qualitative magnetic resonance imaging study. J Pediatr 2003;143:171-79

13. Sie LT, Hart AA, van Hof J, et al. Predictive value of neonatal MRI with respect to late MRI findings and clinical outcome. A study in infants with periventricular densities on neonatal ultrasound. $\mathrm{Neu}$ ropediatrics $2005 ; 36: 78-89$

14. Miller SP, Ferriero DM, Leonard C, et al. Early brain injury in premature newborns detected with magnetic resonance imaging is associated with adverse early neurodevelopmental outcome. J Pediatr 2005;147:609-16

15. Nguyen The Tich S, Anderson PJ, Shimony JS, et al. A novel quantitative simple brain metric using MR imaging for preterm infants. AJNR Am J Neuroradiol 2009;30:125-31
16. Papile LA, Burstein J, Burstein R, et al. Incidence and evolution of subependymal and intraventricular hemorrhage: a study of infants with birth weights less than 1,500 gm. J Pediatr 1978;92:529-34

17. Barkovich AJ. Brain and spine injuries in infancy and childhood In: Barkovich AJ, ed. Pediatric Neuroimaging 4th ed. Philadelphia: Lippincott Williams \& Wilkins; 2005:207-26

18. Bell MJ, Ternberg JL, Feigin RD, et al. Neonatal necrotizing enterocolitis. Therapeutic decisions based upon clinical staging. Ann Surg 1978;187:1-7

19. Tan M, Abernethy L, Cooke R. Improved head growth in preterm infants-a randomised controlled trial II: MRI and developmental outcomes in the first year. Arch Dis Child Fetal Neonatal Ed 2008;93:F342-46

20. Murphy BP, Inder TE, Huppi PS, et al. Impaired cerebral cortical gray matter growth after treatment with dexamethasone for neonatal chronic lung disease. Pediatrics 2001;107:217-21

21. Smith GC, Gutovich J, Smyser C, et al. Neonatal intensive care unit stress is associated with brain development in preterm infants. Ann Neurol 2011;70:541-49

22. Brummelte S, Grunau RE, Chau V, et al. Procedural pain and brain development in premature newborns. Ann Neurol 2012;71:385-96

23. Volpe JJ. Cerebellum of the premature infant: rapidly developing, vulnerable, clinically important. J Child Neurol 2009;24:1085-104

24. Limperopoulos C, Benson CB, Bassan H, et al. Cerebellar hemorrhage in the preterm infant: ultrasonographic findings and risk factors. Pediatrics 2005;116:717-24

25. Northam GB, Liégeois F, Chong WK, et al. Total brain white matter is a major determinant of IQ in adolescents born preterm. Ann Neurol 2011;69:702-11

26. Nagy Z, Ashburner J, Andersson J, et al. Structural correlates of preterm birth in the adolescent brain. Pediatrics 2009;124:e964-72

27. Inder TE, Warfield SK, Wang $\mathrm{H}$, et al. Abnormal cerebral structure is present at term in premature infants. Pediatrics 2005;115:286-94

28. Srinivasan L, Dutta R, Counsell SJ, et al. Quantification of deep grey matter in preterm infants at term-equivalent age using manual volumetry of 3-Tesla magnetic resonance images. Pediatrics 2007;119:759-65

29. Van Kooij BJ, Benders MJ, Anbeek P, et al. Cerebellar volume and proton magnetic resonance spectroscopy at term, and neurodevelopment at 2 years of age in preterm infants. Dev Med Child Neurol 2012;54:260-66

30. Parker J, Mitchell A, Kalpakidou A, et al. Cerebellar growth and behavioral \& neuropsychological outcome in preterm adolescents. Brain 2008;131:1344-51

31. Boardman JP, Counsell SJ, Reuckert D, et al. Abnormal deep gray matter development following preterm birth detected using deformation-based morphometry. Neuroimage 2006;32:70-78

32. Lin Y, Okumura A, Hayakawa F, et al. Quantitative evaluation of thalami and basal ganglia in infants with periventricular leukomalacia. Dev Med Child Neurol 2001;43:481-85

33. Zubiaurre-Elorza L, Soria-Pastor S, Junqué C, et al. Thalamic changes in a preterm sample with periventricular leukomalacia: correlation with white-matter integrity and cognitive outcome at school age. Pediatr Res 2012;71:354-60

34. Stoll BJ, Hansen NI, Adams-Chapman I, et al. Neurodevelopmental and growth impairment among extremely low-birth-weight infants with neonatal infection. JAMA 2004;292:2357-65

35. Short EJ, Klein NK, Lewis BA, et al. Cognitive and academic consequences of bronchopulmonary dysplasia and very low birth weight: 8-year-old outcomes. Pediatrics 2003;112:e359

36. Lucas A, Morley R, Cole TJ. Randomised trial of early diet in preterm babies and later intelligence quotient. BMJ 1998;317:1481-87

37. Spittle AJ, Doyle LW, Anderson PJ, et al. Reduced cerebellar diameter in very preterm infants with abnormal general movements. Early Hum Dev 2010;86:1-5

38. Tich SN, Anderson PJ, Hunt RW, et al. Neurodevelopmental and perinatal correlates of simple brain metrics in very preterm infants. Arch Pediatr Adolesc Med 2011;165:216-22 